\title{
Article
}

\section{The Study of Personality Architecture and Dynamics (SPeADy): A Longitudinal and Extended Twin Family Study}

\author{
Christian Kandler ${ }^{1}$, Angelika Penner ${ }^{2}$, Julia Richter ${ }^{2}$ and Alexandra Zapko-Willmes ${ }^{1}$ \\ ${ }^{1}$ Department of Psychology, University of Bremen, Bremen, Germany and ${ }^{2}$ Department of Psychology, Bielefeld University, Bielefeld, Germany
}

\begin{abstract}
The Study of Personality Architecture and Dynamics (SPeADy) is a German research project that aims to investigate the sources of interindividual differences in intraindividual personality development. The main focus lies in the dynamic interplay between more stable core characteristics and more environmentally malleable surface characteristics, as well as between personality and life experiences over time. SPeADy includes a twin family study encompassing data from 1962 individuals (age: 14-94) of 682 families, including 570 complete twin pairs (plus 1 triplet set), 327 parents, 236 spouses and 145 children of twins. Data collection started in 2016 and data from the first wave are currently obtainable as open source. Available data comprise a broad range of personality variables, such as personality trait constructs, motives, interests, values, moral foundations, religiosity and self-related concepts. For the currently ongoing second wave of data collection, we added retrospective reports on major life events. Special features of this genetically informative study are the extended twin family data and its longitudinal design. Three assessment waves in 2 years' intervals are planned until 2022. In this article, we briefly describe the design and contents of the SPeADy twin family study as well as some recent findings, future plans and open science issues.
\end{abstract}

Keywords: Extended twin family design; longitudinal study; personality; SPeADy; core and surface characteristics

(Received 22 March 2019; accepted 22 July 2019; First Published online 9 September 2019)

\section{Research Focus and Aims}

'Personality' has often been defined, operationalized and very sparingly investigated with a small set of descriptive trait constructs, such as the Big Five dimensions (Digman, 1990; Goldberg, 1990). However, this reductionist view is questionable for at least two reasons. First, 'personality' is commonly defined and conceptualized as relatively enduring characteristic patterns of a person's behaviors - including emotions, cognitions and motivations - in comparison with a reference population (Baumert et al., 2017; Kandler et al., 2014). Second, relative low structural and etiological overlap has been found between operationalizations of broad personality trait dimensions and other relatively stable characteristics, such as motives, values and interests (Kandler et al., 2014).

A sufficiently comprehensive model of personality should encompass all characteristics that are essential to reflect dispositions to feeling, thinking, striving and behaving of a person compared to other persons. These characteristics must capture dispositional individuality in its entirety. This raises questions as to what core characteristics are and which other (surface) characteristics merely result from combinations of specific core characteristics or interactions between these characteristics and experiences during development (Kandler et al., 2017). The 'Study of Personality Architecture and Dynamics' (SPeADy) deals with those questions and aims to answer them with the use of longitudinal and genetically informative data.

Author for correspondence: Christian Kandler, Email: ckandler@uni-bremen.de Cite this article: Kandler C, Penner A, Richter J, and Zapko-Willmes A. (2019) The Study of Personality Architecture and Dynamics (SPeADy): A Longitudinal and Extended Twin Family Study. Twin Research and Human Genetics 22: 548-553, https://doi.org/10.1017/thg.2019.62
The combination of longitudinal and behavior genetic designs allows testing for the conceptualization of some traits as core characteristics (e.g., neuroticism and extraversion) and other individual features as surface characteristics (e.g., self-esteem and control beliefs) on the basis of five proposed criteria (see Figure 1 for visualizations and descriptions of all criteria; Asendorpf \& MottiStefanidi, 2018; Kandler et al., 2014). SPeADy thus allows the empirical falsification of several existing personality models. Based on a conceptualization of 'personality' as a dynamic network of core and surface characteristics, SPeADy enables unique implications for an integrative model that describes and explains personality differences and development. Importantly, this dynamic network may stabilize or change and may be more or less consistent across time and situations as a function of age and its interplay with the individual environment.

The twin family study of SPeADy has been designed to collect data that allow empirical tests of all criteria, particularly the second, fourth and fifth criterion. Extending a classical twin design by including data from parents, spouses and offspring of twins help overcome many limitations of a twins-only design. For instance, it reduces the indeterminacy and distortion of estimates of genetic and environmental contributions to individual differences (Keller et al., 2010). Furthermore, the longitudinal nature of our design allows implications for the direction of causation (Turkheimer \& Harden, 2014).

\section{Sample Recruitment and Data Collection from 2016 to 2018}

The first wave of data collection started in January 2016. As Germany has no national twin registry, we used different strategies

(c) The Author(s) 2019. This is an Open Access article, distributed under the terms of the Creative Commons Attribution licence (http://creativecommons.org/licenses/by/4.0/), which permits unrestricted re-use, distribution, and reproduction in any medium, provided the original work is properly cited. 
Table 1. Characteristics for the twin family sample of the Study of Personality Architecture and Dynamics (SPeADy)

\begin{tabular}{|c|c|c|c|c|c|c|}
\hline \multicolumn{7}{|c|}{ Twin family members } \\
\hline No. per zygosity & Twins & Twin pairs & Mother & Father & Spouse & Offspring \\
\hline Monozygotic & 442 & 221 & 64 & 41 & 111 & 69 \\
\hline Dizygotic & 698 & 349 & 135 & 74 & 117 & 74 \\
\hline Unmatched & 111 & - & 8 & 3 & 8 & 2 \\
\hline Female in $\%$ & 72 & 73 & 100 & 0 & 27 & 62 \\
\hline Age range & $14-88$ & $14-88$ & $37-87$ & $35-85$ & $16-94$ & $14-59$ \\
\hline
\end{tabular}

Note: In addition, one triplet family (including the triplet's parents) participated in SPeADy. Unmatched = twins' zygosity unknown.

(1)

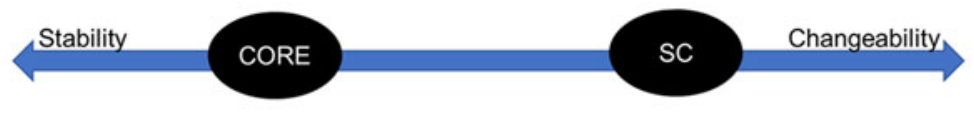

(2)

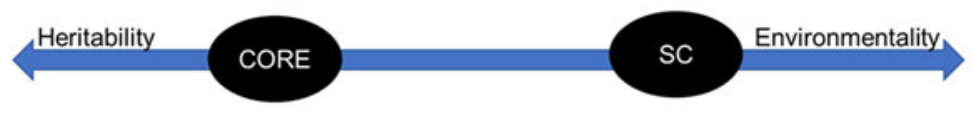

(3)

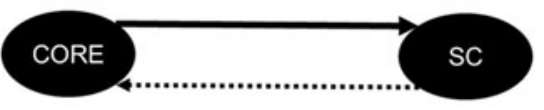

Fig. 1. (Color online) Illustration of the five criteria to conceptually and empirically differentiate between core personality (CORE) and surface characteristics (SC): Core characteristics are (1) more stable, (2) less environmentally malleable, (3) they shape surface characteristics rather than vice versa, (4) genetic variance in surface characteristics should be completely accounted for by genetic variance in core characteristics and (5) surface characteristics mediate the effects from core characteristics on the environment (selection effects) and vice versa (socialization effects).
(4)

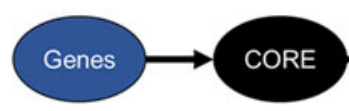

$\mathrm{SC}$

(5)

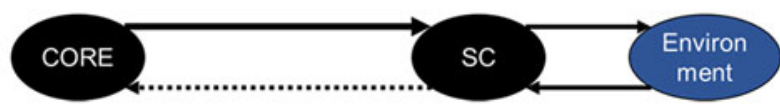

to recruit twins and their family members. First, twin families were invited to participate through several media calls (e.g., newspapers, leaflets, posters, internet, radio and TV). Second, we approached twin clubs in Germany and provided information on SPeADy at twin meetings. Third, we contacted registration offices of big German cities to gain access to contact details from families with twins between 14 and 18 years of age reared together (i.e., individuals with the same birth date, family name and address). After providing a declaration to use the data only for scientific purposes and to protect personal rights and data privacy, we received contact information from registration offices of five cities (Berlin, Essen, Düsseldorf, Bielefeld and Herford). Registration offices from 15 other cities in North Rhine-Westphalia and Lower Saxony did not respond, declined to cooperate or argued that their used computer software did not allow retrieval of the data we asked for. Fourth, we tried to recruit older twins with contact details from two former twin studies: The Jena Twin Study of Social Attitudes (Stößel et al., 2006) and the Bielefeld Longitudinal Study of Adult Twins (Kandler et al., 2013).

Contacted twins were referred to the project's homepage for online participation or could call an installed telephone hotline for more information on the study's purpose, participation and compensation. All participants provided an informed consent. Twins could decide to provide data via an online survey using Questback's Unipark (www.unipark.com/en) or via completing a set of mailed questionnaires. Twins received a personality profile and a $10 €$ voucher (a so-called BestChoice shopping gift card) after both twins of a pair had taken part in the study. Other twin family members received a personality profile and could enter into a lottery drawing for vouchers of $10-500 €$ as compensation for participation. Contact details were entered into a different database than research data. The latter are available in a pseudonymized format. That is, they can only be combined with the contact details via a personal code generated by each participant. Twins were asked to provide contact details of their parents, spouses or offspring if they were also interested to participate. These twin family members were subsequently contacted via email or mailed questionnaires. More than 2500 twin families were contacted via postal mail. Approximately 4000 individuals clicked on the link to the online survey. About half of them finished the survey. The data collection of the initial wave ended in January 2018.

A total of 1962 individuals from 682 families participated in the first wave of the twin family data collection, about $74 \%$ via online survey and $26 \%$ by mail. The SPeADy twin family sample includes data from 570 complete twin pairs (including 171 female and 50 male monozygotic pairs, 194 female and 57 male same-sex dizygotic pairs, and 98 opposite-sex dizygotic pairs), 208 mothers and 119 fathers, 236 spouses and 145 offspring of twins (see Table 1). The sample cannot be treated as representative for the German population, but it can be seen as heterogeneous with respect to age (range: $14-94)$, gender (64\% females), family status ( $42 \%$ unwed, $48 \%$ married, $7 \%$ divorced, $3 \%$ widowed) and educational level (12\% at school, $8 \%$ school-leaving qualification, $18 \%$ secondary school certificate, $9 \%$ polytechnic degree, $20 \%$ high school graduation, $31 \%$ academic degree, and $2 \%$ others and no school-leaving qualification). 
Table 2. Summary of measures used in the Study of Personality Architecture and Dynamics (SPeADy)

\begin{tabular}{|c|c|c|c|c|}
\hline Measures & No. of items & Wave 1 & Wave 2 & Wave 3 \\
\hline \multicolumn{5}{|l|}{ Demographics and zygosity } \\
\hline Age, sex, nationality, etc. & 13 & $x$ & $x$ & $x$ \\
\hline Zygosity questionnaire & 24 & $x$ & $(\mathrm{X})$ & \\
\hline \multicolumn{5}{|l|}{ Personality trait models } \\
\hline BFI-2 (five-factor model) & 60 & $x$ & & \\
\hline HEXACO-60 (HEXACO model) & 60 & $x$ & $x$ & $x$ \\
\hline \multicolumn{5}{|l|}{ Self-related concepts } \\
\hline HSWBS (affective wellbeing) & 6 & $x$ & $x$ & $x$ \\
\hline SWLS (cognitive wellbeing) & 5 & $x$ & $x$ & $x$ \\
\hline RSES (self-esteem) & 3 & $x$ & $x$ & $x$ \\
\hline IE-4 (control beliefs) & 4 & $x$ & $x$ & $x$ \\
\hline ASKU-3 (self-efficacy beliefs) & 3 & $x$ & $x$ & $x$ \\
\hline OPS-Scales (control strategies) & 7 & $x$ & & \\
\hline MacArthur SSS (subj. social status) & 1 & $x$ & & \\
\hline Picture-anchored AR (attractiveness) & 1 & $x$ & & \\
\hline Nonanchored AR (attractiveness) & 1 & $x$ & $x$ & $x$ \\
\hline \multicolumn{5}{|l|}{ Goals, motives and interests } \\
\hline SIT (interests) & 30 & $x$ & & \\
\hline UMS-24 (motives) & 24 & $X$ & $x$ & $x$ \\
\hline Al: Personal growth (motives) & 5 & $x$ & $x$ & $x$ \\
\hline Al: Health (motives) & 5 & $x$ & & \\
\hline \multicolumn{5}{|l|}{ Morality, values and religiosity } \\
\hline MFQ-21 (morality) & 21 & $x$ & & \\
\hline PVQ-57-RR (values) & 57 & $x$ & $x$ & $x$ \\
\hline Z7 (religiosity) & 7 & $x$ & $x$ & $x$ \\
\hline Major life events & 24 & & $\leftarrow X$ & $\leftarrow X$ \\
\hline
\end{tabular}

Note: $\mathrm{X}$ : captured, or planned to capture, in the wave of data collection; $(\mathrm{X})$ : only given to new participants of the second wave; $\leftarrow \mathrm{X}$ : retrospective reports on life events. BFI-2 = Big Five Inventory 2 (adapted from Danner et al., 2019; Soto \& John, 2017); HEXACO-60 = 60-item HEXACO Personality Inventory Revised (Ashton \& Lee, 2009; Moshagen et al., 2014); HSWBS = Habitual Subjective Well-Being Scale (Dalbert, 1992); SWLS = Satisfaction With Life Scale (Diener et al., 1985; Glaesmer et al., 2011); RSES = Rosenberg Self-Esteem Scale (Rosenberg, 1965; adapted from Thönnissen et al., 2014); IE-4 = 4-Item-Scale for the Assessment of Internal and External Control Beliefs (Kovaleva, 2012; Kovaleva et al., 2012); MacArthur SSS = MacArthur Scale of Subjective Social Status (https://macses.ucsf.edu/research/psychosocial/ usladder.php; Adler et al., 2000); Picture-anchored AR = Picture-anchored Attractiveness Rating (Kemper et al., 2012); Nonanchored AR $=$ Nonanchored Attractiveness Rating (developed for SPeADy); ASKU-3 = Short Scale for Measuring General Self-Efficacy Beliefs (Beierlein et al., 2012); OPS-Scales = Optimization in Primary and Secondary Control — A Multiscale Questionnaire (adapted from Heckhausen et al., 1998); SIT = Situative Interest Test (https://www.stangl-taller.at/ARBEITSBLAETTER/TEST/SIT/beschreibung.shtml); UMS-24 = Unified Motive Scales (Schönbrodt \& Gerstenberg, 2012); AI = Aspirations Index (Klusmann et al., 2005; http://selfdeterminationtheory.org/ aspirations-index/); MFQ-21 = 21-item Moral Foundations Questionnaire (www.moralfoundations.org/questionnaires); PVQ-57RR = Portrait Value Questionnaire (https://mindcultureevolution.com/revised-portrait-value-questionnaire-57rr/; Schwartz et al., 2012); Z7 = Centrality of Religiosity Scale (Huber \& Huber, 2012); newly developed Life Event Check List inspired by Kandler and Ostendorf (2016).

The sets of inventories of the first wave included a demographic questionnaire (including age, sex, education, occupational status, nationality, family status, relationship status and length, religious affiliation, and number of biological offspring), several established, cost-effective (uncommercial and time-efficient) questionnaires capturing personality traits, motives, interests, values and wellbeing, and a self-report questionnaire determining zygosity. Online participants needed about $45-65 \min (M=55 ; S D=5)$ to fully complete the questionnaires in the first wave. All measures showed at least acceptable internal consistency $(\alpha / \omega \geq .70)$ and self-other agreement $(r>.35)$. Table 2 provides an overview of the used questionnaires and the planned use in the different waves of data collection.

\section{Data Collection from 2018 to 2022}

We aim to contact each participant again about 2 years (second wave: February 2018-January 2020) and 4 years (third wave: February 2020-January 2022) after their first participation. To avoid mobility-induced sample dropout, we ask participants to inform us about any changes of contact details between assessment waves. In addition, new twin families can participate in the second wave to counteract the decrease of statistical power of the longitudinal sample due to attrition over time. We continue to use the recruitment strategies of the first wave for the consecutive waves, but less extensively. We spend more time and effort guaranteeing panel stability. 
To reduce the effort for each participant, we shortened the set of questionnaires for the second wave of data collection (see Table 2), decreasing the time required to complete the questionnaires to an average of $30 \mathrm{~min}$. We added a comprehensive list of life events, newly developed for SPeADy. This list includes categories of typical life events (e.g., accident, significant improvement or deterioration of financial situation, divorce, new romantic relationship) that could have happened in the 2 years after their last participation (i.e., the time span between measurement occasions). Participants are asked to state whether they have experienced a certain kind of life event or not, and if they had, to rate its subjective controllability and individual valence. The life event checklist has been added to analyze the interdependence between life experiences and personality development (see fifth criterion in Figure 1).

\section{Major Findings}

After cleansing of data (e.g., correction or exclusion of flawed and implausible data) of the first wave, we ran initial analyses and presented first results of preliminary analyses at the 19th European Conference on Personality 2018 in Zadar, Croatia. In the following, we outline three examples of recent major findings.

\section{Nature and Nurture of HEXACO Personality Traits}

We added to existing knowledge on the sources of individual differences in HEXACO personality characteristics. Extended twin family analyses using structural equation modeling yielded that additive and nonadditive genetic influences accounted for about $50 \%$ of the variance in personality traits. Broad-sense heritability estimates ranged from .30 for Honesty-Humility to .65 for Openness. The remaining variance was primarily due to individualspecific environmental sources and random error of measurement. Spousal similarity in Openness was attributable to assortative mating acting to stabilize or increase genetic variance, whereas spousal similarity in Honesty-Humility was attributable to environmental sources, partly due to a shared social background and spousespecific effects. Whereas the latter increased the similarity of spouses only, the former drove to increase the similarity among all family members. Effects due to shared social background accounted for $16 \%$ of the variance in Honesty-Humility, while $10 \%$ of the variance was due to spouse-specific interaction. In line with previous studies, however, we found that the transmission of trait similarity from one generation to the next was exclusively genetic with the exception of small variance components due to passive gene-environment correlation (about 2\%) for Openness and Extraversion (see Kandler et al., 2019, for more details).

\section{Nature and Nurture of Morality}

In their moral foundations theory, Haidt and Joseph (2004) proposed innate, universally observable moral intuitions that allow us to approve or disapprove acts or events involving other human beings, to ensure social life. These can be organized in at least five moral intuitions: Care (i.e., avoiding harm to others), Fairness (i.e., ensuring fair treatment for all), Loyalty (i.e., protecting the social institutions that are family, community and country), Authority (i.e., complying with duty, authorities, laws and tradition) and Sanctity (i.e., maintaining purity of body and mind) (Haidt \& Joseph, 2007). We estimated genetic and environmental sources of individual differences in these moral intuitions using a latent variable approach to control for error of measurement (Kandler \& Zapko-Willmes, 2017). The results suggest that individual differences in Care and Fairness were primarily due to genetic influences (73\% and 51\%) and individual-specific environmental factors ( $27 \%$ and $48 \%$ ), whereas variance in Loyalty and Authority was primarily attributable to environmental influences shared by twins (31\% and 36\%) and not shared by family members (69\% and 60\%). Sanctity showed significant genetic (28\%) and shared environmental (38\%) as well as nonshared environmental variance components (34\%). These results are comparable with the findings of an Australian twin study, which yielded strong effects of individual environmental influences, but moderate or marginal genetic effects on individual differences in intuitive moral judgments, in particular, for Loyalty and Authority (Smith et al., 2017). Additional latent factor analyses indicated that a common factor of Care and Fairness (i.e., moral focus on social vs. individual outcomes) mediated most of the genetic variance in these variables (65\% and 100\%), whereas a common dimension of Loyalty, Authority and Sanctity (i.e., moral focus on organization vs. opportunity) mediated most of their shared environmental variance components (100\%, $71 \%$ and $67 \%)$.

\section{Genetic and Environmental Links Between Morality and Value Priorities}

As previous studies have found substantial genetic differences (about 40-50\%) in core human value orientations (e.g., Kandler et al., 2016), such as conservation versus open-minded values (CO) and self-transcendent versus self-enhancing values (SS), we investigated the sources of the links between value orientations and major foci of moral concern as well as HEXACO personality traits. The findings indicated that value orientations may rather reflect core characteristics, whereas foci of moral concern represented surface characteristics of the same underlying innate tendencies. $\mathrm{CO}$ and a moral focus on organization versus opportunity were substantially correlated $(r=.45)$. These dimensions showed moderate genetic and environmental overlap. CO was negatively associated with the personality trait Openness to Experience $(r=-.26)$ and mediated its positive link with a moral focus on opportunity $(r=.17)$. The association between SS and a moral focus on social versus individual outcomes $(r=.28)$ was solely due to environmental sources. In addition, SS showed a substantial positive link with the personality trait HonestyHumility $(r=.61)$ and mediated its positive association with a moral focus on social outcomes $(r=.14)$. These results indicated that innate core human motives linked to all of these characteristics - strivings to get ahead versus along and growth versus stability - may underlie the systematic links between specific personality trait concepts, core value orientations and foci of moral concerns (see ZapkoWillmes, 2018).

\section{Future Plans and Open Data}

Several further study projects are currently in progress. For example, we are investigating the architecture and the sources of the links between personality traits and value priorities on various levels of abstraction (i.e., dimensions, domains, facets and nuances). Further, we will examine the etiology of the transaction between life events and subjective wellbeing over time as well as how control beliefs moderate this association. Moreover, we are currently examining age differences in the genetic and environmental component of HEXACO personality traits across the lifespan based on twin data from the German SPeADy and from two other nations (Croatia and the UK). The major aim of 
SPeADy, however, is the critical test of the criteria presented in Figure 1 for several personality-related constructs.

SPeADy data of the first wave are already available as an anonymized Scientific Use File on request. Data of the second and third wave are planned to be available in April 2020 and April 2022, respectively. Researchers are welcome to contact us and to provide a short outline of their research plans (see www.speady.de/studies/?lang=en for more details).

Acknowledgments. We thank the whole SPeADy team as well as the twins and their family members for spending part of their lifetime with the research project. In particular, we thank former team members, Michael Papendick, Hannah Sarnizei, Paula Wundersee, Rebecca Gruzman, Pauline Hirche, Julia Schneider, Kai Tippelt and Felix Butt for their important contributions to the current study.

Financial support. This research (www.speady.de/?lang=en) is supported by grants from the German Research Foundation awarded to Christian Kandler (KA-4088/2-1 and KA-4088/2-2).

\section{Conflict of interest. None.}

Ethical standards. The authors assert that all procedures contributing to this work comply with the ethical standards of the relevant national and institutional committees on human experimentation and with the Helsinki Declaration of 1975 , as revised in 2008 .

\section{References}

Adler, N. E., Epel, E. S., Castellazzo, G., \& Ickovics, J. R. (2000). Relationship of subjective and objective social status with psychological and physical health: Preliminary data in healthy white women. Health Psychology, 19, 585-591.

Asendorpf, J. B., \& Motti-Stefanidi, F. (2018). Mediated disposition-environment transactions: The DAE model. European Journal of Personality, 32, 167-185.

Ashton, M. C., \& Lee, K. (2009). The HEXACO-60: A short measure of the major dimensions of personality. Journal of Personality Assessment, 91, 340-345.

Baumert, A., Schmitt, M., Perugini, M., Johnson, W., Blum, G., Borkenau, P., ... Wrzus, C. (2017). Integrating personality structure, personality process, and personality development. European Journal of Personality, 31, 503-528

Beierlein, C., Kovaleva, A., Kemper, C. J., \& Rammstedt, B. (2012). Ein Messinstrument zur Erfassung subjektiver Kompetenzerwartungen: Allgemeine Selbstwirksamkeit Kurzskala (ASKU) [An instrument to measure subjective competence expectation: General self-efficacy short scale (ASKU)]. (GESIS-Working Papers, 2012/17). Mannheim: GESIS Leibniz-Institut für Sozialwissenschaften. Retrieved from https://nbnresolving.org/urn:nbn:de:0168-ssoar-292351

Dalbert, C. (1992). Subjektives Wohlbefinden junger Erwachsener: Theoretische und empirische Analysen der Struktur und Stabilität [Young adults' subjective well-being: Theoretical and empirical analyses of its structure and stability]. Zeitschrift für Differentielle und Diagnostische Psychologie, 13, 207-220.

Danner, D., Rammstedt, B., Bluemke, M., Lechner, C., Berres, S., Knopf, T., .. John, O. P. (2019). Das Big Five Inventar 2: Validierung eines Persönlichkeitsinventars zur Erfassung von 5 Persönlichkeitsdomänen und 15 Facetten [The Big Five Inventory 2: Validation of a personality inventory for measuring 5 personality domains and 15 facets]. Diagnostica, 65, 121-132.

Diener, E., Emmons, R. A., Larsen, R. J., \& Griffin, S. (1985). The satisfaction with life scale. Journal of Personality Assessment, 49, 71-75.

Digman, J. M. (1990). Personality structure: Emergence of the five-factor model. Annual Review of Psychology, 41, 417-440.

Glaesmer, H., Grande, G., Braehler, E., \& Roth, M. (2011). The German version of the satisfaction with life scale (SWLS). European Journal of Psychological Assessment, 27, 127-132.
Goldberg, L. R. (1990). An alternative 'description of personality': The Big-Five factor structure. Journal of Personality and Social Psychology, 59, 1216-1229.

Haidt, J., \& Joseph, C. (2004). Intuitive ethics: How innately prepared intuitions generate culturally variable virtues. Daedalus, 133, 55-66.

Haidt, J., \& Joseph, C. (2007). The moral mind: How five sets of innate intuitions guide the development of many culture-specific virtues, and perhaps even modules. In P. Carruthers, S. Laurence, \& S. Stich (Eds.), The innate mind (vol. 3, pp. 367-391). New York, NY: Oxford University Press.

Heckhausen, J., Schulz, R., \& Wrosch, C. (1998). Developmental regulation in adulthood: Optimization in primary and secondary control - A multiscale questionnaire (OPS-Scales; Technical report). Berlin, Germany: MaxPlanck-Institute for Human Development.

Huber, S., \& Huber, O. W. (2012). The Centrality of Religiosity Scale (CRS). Religions, 3, 710-724.

Kandler, C., Gottschling, J., \& Spinath, F. M. (2016). Genetic and environmental parent-child transmission of value orientations: An extended twin family study. Child Development, 78, 270-284.

Kandler, C., \& Ostendorf, F. (2016). Additive and synergetic contributions of neuroticism and life events to depression and anxiety in women. European Journal of Personality, 30, 390-405.

Kandler, C., Penner, A., \& Zapko-Willmes, A. (2017). Core and surface characteristics of personality. In V. Zeigler-Hill \& T. K. Shackelford (Eds.), Encyclopedia of personality and individual differences. Cham, Switzerland: Springer.

Kandler, C., Richter, J., \& Zapko-Willmes, A. (2019). The nature and nurture of HEXACO personality trait differences: An extended twin family study. Zeitschrift für Psychologie, 227, 195-206.

Kandler, C., Riemann, R., Spinath, F. M., Bleidorn, W., Thiel, W., \& Angleitner, A. (2013). The Bielefeld Longitudinal Study of Adult Twins (BiLSAT). Twin Research and Human Genetics, 16, 167-172.

Kandler, C., \& Zapko-Willmes, A. (2017, June-July). The genetic and environmental foundations of morality. Paper presented at the 47th annual meeting of the Behavior Genetics Association, Oslo, Norway.

Kandler, C., Zimmermann, J., \& McAdams, D. P. (2014). Core and surface characteristics for the description and theory of personality differences and development. European Journal of Personality, 28, 231-243.

Keller, M. C., Medland, S. E., \& Duncan, L. E. (2010). Are extended twin family designs worth the trouble? A comparison of the bias, precision, and accuracy of parameters estimated in four twin family models. Behavior Genetics, 40, 377-393.

Kemper, C. J., Lutz, J., Margraf-Stiksrud, J., Beierlein, C., Kovaleva, A., \& Rammstedt, B. (2012). Eine Ein-Item-Skala zur Einschätzung von Attraktivität: Das Attraktivitätsrating (AR1) [A one-item-scale for the assessment of attractiveness: The attractiveness rating (AR1)]. (GESISWorking Papers, 2012/24). Mannheim: GESIS- Leibniz-Institut für Sozialwissenschaften. Retrieved from https://nbn-resolving.org/urn:nbn:de: 0168-ssoar-317137

Klusmann, U., Trautwein, U., \& Lüdtke, O. (2005). Intrinsische und extrinsische Lebensziele [Intrinsic and extrinsic personal goals: Reliability and validity of a German translation of the Aspirations Index]. Diagnostica, 51, 40-51.

Kovaleva, A. (2012). The IE-4: Construction and validation of a short scale for the assessment of locus of control. (GESIS-Schriftenreihe, 9). Cologne: GESIS - Leibniz-Institut für Sozialwissenschaften. Retrieved from https://nbnresolving.org/urn:nbn:de:0168-ssoar-371199

Kovaleva, A., Beierlein, C., Kemper, C. J., \& Rammstedt, B. (2012). Eine Kurzskala zur Messung von Kontrollüberzeugung: Die Skala Internale-Externale-Kontrollüberzeugung-4 (IE-4). [A short scale measuring control beliefs: The scale internal-external-control-4 (IE-4)]. (GESISWorking Papers, 2012/19). Mannheim: GESIS - Leibniz-Institut für Sozialwissenschaften. Retrieved from https://nbn-resolving.org/urn:nbn:de: 0168-ssoar-312096

Moshagen, M., Hilbig, B. E., \& Zettler, I. (2014). Faktorenstruktur, psychometrische Eigenschaften und Messinvarianz der deutschsprachigen Version des 60-Item HEXACO Persönlichkeitsinventars [Factor structure, psychometric properties, and measurement invariance of the German-language version of the 60-item HEXACO Personality Inventory]. Diagnostica, 60, 86-97. 
Rosenberg, M. (1965). Society and the adolescent self-image. Princeton, NJ: Princeton University Press.

Schönbrodt, F. D., \& Gerstenberg, F. X. R. (2012). An IRT analysis of motive questionnaires: The Unified Motive Scales. Journal of Research in Personality, 46, 725-742.

Schwartz, S. H., Cieciuch, J., Vecchione, M., Davidov, E., Fischer, R., Beierlein, C., ... Konty, M. (2012). Refining the theory of basic individual values. Journal of Personality and Social Psychology, 103, 663-688.

Smith, K. B., Alford, J. R., Hibbing, J. R., Martin, N. G., \& Hatemi, P. K. (2017). Intuitive ethics and political orientations: Testing moral foundations as a theory of political ideology. American Journal of Political Science, 61, 424-437.

Soto, C. J., \& John, O. P. (2017). The next Big Five Inventory (BFI-2): Developing and assessing a hierarchical model with 15 facets to enhance bandwidth, fidelity, and predictive power. Journal of Personality and Social Psychology, 113, 117-143.
Stößel, K., Kämpfe, N., \& Riemann, R. (2006). The Jena Twin Registry and the Jena Twin Study of Social Attitudes (JeTSSA). Twin Research and Human Genetics, 9, 783-786.

Thönnissen, C., Gschwendtner, C., Wilhelm, B., Friedrich, S., Wendt, E.-V., \& Walper, S. (2014). Scales manual of the German family panel. Waves 1 to 5 (Release 5.0). Retrieved from http://www.pairfam.de/fi leadmin/user_upload/ redak-teur/publis/Dokumentation/Manuals/Scales_Manual_pairfam_5.0.pdf

Turkheimer, E., \& Harden, K. P. (2014). Behavior genetic research methods. In H. T. Reis \& C. M. Judd (Eds.), Handbook of research methods in social and personality psychology (pp. 159-187). Cambridge, UK: Cambridge University Press.

Zapko-Willmes, A. (2018). Sources of individual differences in sociopolitical orientations: Findings from combining behavior genetic with multi-rater approaches. Bielefeld, Germany: Universität Bielefeld. doi:10.4119/unibi/ 2932598 